\title{
Branching pattern of mental nerves in south Indian population: A cadaveric dissection study
}

\author{
Sipra Rout ${ }^{1}$, Priyanka Daniel ${ }^{2, *}$, J. Suganthy ${ }^{3}$ \\ ${ }^{1,2}$ Assistant Professor, ${ }^{3}$ Professor, Dept. of Anatomy, Christian Medical College, Vellore, Tamil Nadu, India
}

*Corresponding Author: Priyanka Daniel

Email: priyanka.daniel@gmail.com

Received: $25^{\text {th }}$ July, 2018

Accepted: $18^{\text {th }}$ September, 2018

\begin{abstract}
Introduction: Knowledge of branching pattern of mental nerve (MN) at mental foramen (MF) along with prevalence of accessory mental foramen (AMF) exhibiting accessory mental nerve (AMN) is an obligatory consideration in orthodontics like osteotomy reconstructive procedures, placement of implants, nerve blocks. It has been reported to show population differences regarding these in various osteological studies. However no cadaveric study is reported in South Indian population so far.

Aim: To analyze the branching pattern of $\mathrm{MN}$ at its emergence, to determine the location of MF in relation to mandibular teeth and to study the frequency of occurrence of AMF with the structures emerging through it in South Indian population.

Materials and Methods: 30 cadavers were dissected bilaterally, exposing the mental foramen. Terminal branches of MN at the foramen were carefully dissected and their distribution was noted. The position of MFs and AMFs were noted in relation to mandibular teeth. The AMN (if present) was carefully dissected and noted. The mean distance between accessory mental foramen and mental foramen was also measured.

Results: A single MN was noted in all the cadaveric specimens $(n=60)$. The MN most commonly branched into two branches in $51.66 \%$ of cases. The location of MF was found to be inferior to the second premolar on either side in $66 \%$ cases. The AMF with AMN passing through it was found only in $3.3 \%$ of cases.

Conclusion: The commonest pattern of MN observed was MN dividing into 2 branches at the MF. Though high prevalence of AMF noted, not all AMF exhibited AMN.
\end{abstract}

Keywords: Mental foramen, Accessory mental foramen, Orthodontics, Mental nerve, Accessory mental nerve, Nerve block.

\section{Introduction}

With increasing trends in usage of dental implants, root canal treatments, and various orthodontic surgeries, the mental foramen (MF) has become a clinically and surgically important landmark. The mental nerve (MN) emerging through it serves an important point of administration of anesthesia for nerve block in surgeries involving the mandible. ${ }^{1}$ Thus identification of $\mathrm{MN}$ along with its cutaneous branches is of paramount importance during presurgical evaluation to achieve effective anesthesia and prevent post operative neurosensory loss by iatrogenic injury. The MN branches show variation from zero to four which supplies the chin, mucous membrane and skin of lower lip and gingiva. ${ }^{2-5}$ The number and position of MF, the branches of $\mathrm{MN}$ at its exit has been described to exhibit variability in different ethnic groups. ${ }^{6}$ In addition to this, the possible occurrence of accessory mental nerve in the vicinity of $\mathrm{MN}$ also requires consideration during procedures like dental implant insertion; implant related bone grafting, genioplasty, mandibular anterior segmented osteotomy to prevent unintended injury to it. This accessory mental foramen (AMF) is an infrequent anatomical variation which has been reported to have a prevalence ranging from 1.4 to $10 \% .^{7}$ Occasionally the AMF gave passage to few capillaries only without accessory mental nerve (AMN). ${ }^{8}$ The knowledge of branching pattern of $\mathrm{MN}$ along with AMN if present is necessary to avoid any inadvertent intraoparative complications. Studies so far are largely based on osteological findings and case reports with not many supportive cadaveric dissections. Thus we feel the cadaveric observations under gross inspection might help in validating with the osteological data in South Indian population. Thus the aim of this study is to observe the branching pattern of $\mathrm{MN}$ in this population along with prevalence of AMF and nature of structures passing through it.

\section{Materials and Methods}

This study was carried out in department of Anatomy of our institution after approval from Institutional Review Board. A total of 60 hemi faces (30R, 30L) with intact lower mandibular teeth and no deformity were dissected for this study. All the cadavers were of South Indian origin being donated to the department for the purpose of teaching and research. The MF was exposed reflecting the skin flap by means of three incisions. One vertical midline incision extending from symphysis menti to middle of lower lip, two lateral horizontal incisions from the midpoint of lower lip to angle of mouth close to mandibular alveolar border and one along the lower border of mandible from symphysis menti. The MF was located by careful skin reflection. Its position was noted in relation to lower teeth. The $\mathrm{MN}$ was carefully dissected and the initial and terminal branching pattern was noted. The presence of AMF was looked for and if 
present was noted, along with the structures emerging from it. The distance between AMF and MF was measured and its position in relation to MF was noted. The data collected was analyzed using Microsoft Excel 2007. The frequency and percentage of various branching pattern, location of MF in respect to lower tooth was determined.

\section{Results}

In the current study, the position of MF was observed to be most commonly located directly inferior to the second premolar in $66.66 \%$ of cases followed by inferior to first premolar in $26.66 \%$. [Table 1] Table 2 shows the various position of AMF in respect to lower mandibular teeth. Though AMF was found in 6 cases, only one case $(3.3 \%)$ was seen transmitting the AMN through it which was located $3 \mathrm{~mm}$ infero lateral to $\mathrm{MF}$ in between second premolar and first molar. The incidence of AMF in current was found to be $10 \%$. [Table 2] The prevalence of AMF was more on the right side [13.3\%] than left in current study. [Table 2]

Out of 60 cadaveric dissection on mandibular area (30 right and 30 left), a single $\mathrm{MN}$ was noted to be emerging in all the cadavers on both sides. The MN divided immediately at the emergence or close to it (1$2 \mathrm{~mm}$ ) into branches which varied from two to four. These branches finally terminated supplying areas over chin, gingival, and mucous membrane of lower lip and angle of mouth. Based on number of branches given by each mental nerve immediately at its emergence, the pattern of branching was classified into 3 types i.e. Type I, Type-II, and Type-III. [Table 3] In type I, two branches were given, the medial branch further divides to supply the area over chin and mucous membrane of medial side of lower lip and lateral one divided to innervate the gingiva and angle of the mouth. [Fig. 1, A] In type -II, MN seen dividing into three branches the medial branch was given to mental region, second branch terminated on mucous membrane of lip and gingiva and the lateral one supplied the angle and sometimes the gingiva. [Fig. 1, B] In type III, the MN divided into 4 separate branches which innervated mental area, mucous membrane of lip, gingiva and angle of mouth respectively. [Fig. 1, C] Type I was observed in $51.66 \%$ of cases followed by $30 \%$ cases showing type II. Only in $18.34 \%$ of cases the MN was noted to split into four separate branches i.e. type III. [Table 3] In one side (3.3\%) where the AMN was present, it supplied the area over the mental region independently with the MN seen splitting into three branches at MF, which innervated mucous membrane of lower lip, gingiva and angle of mouth. [Fig. 2, A] Out of 6 AMFs noted, 5 (showed without any corresponding nerve transmitted through them. [Fig. 2, B]
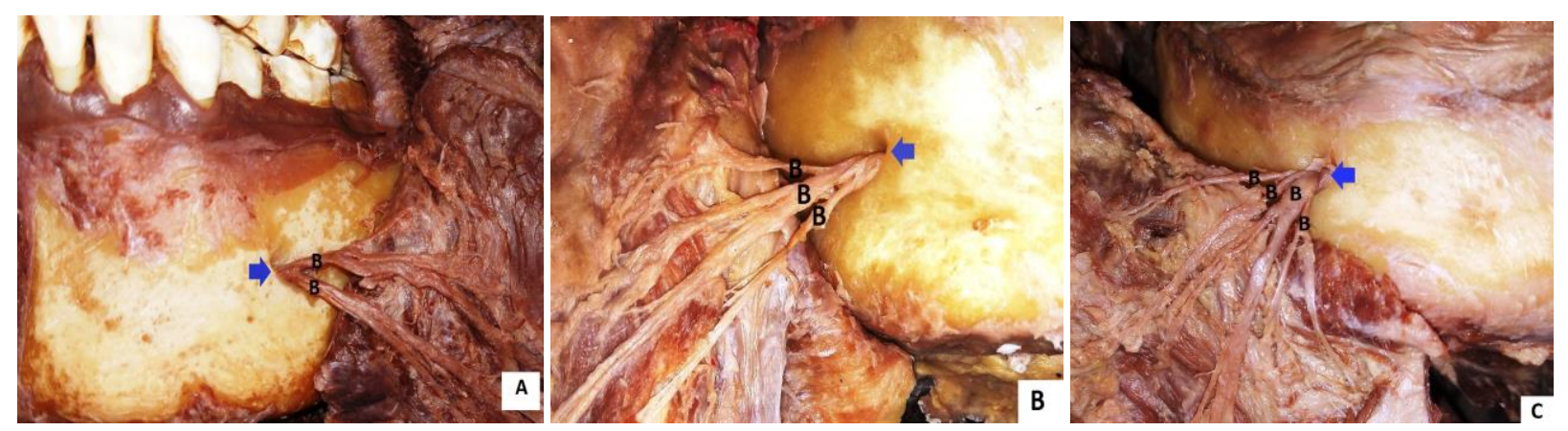

Fig. 1: Photographs showing branches of mental nerve; 1A: 2 branches; 1B: 3 branches; 1 C: 4 branches
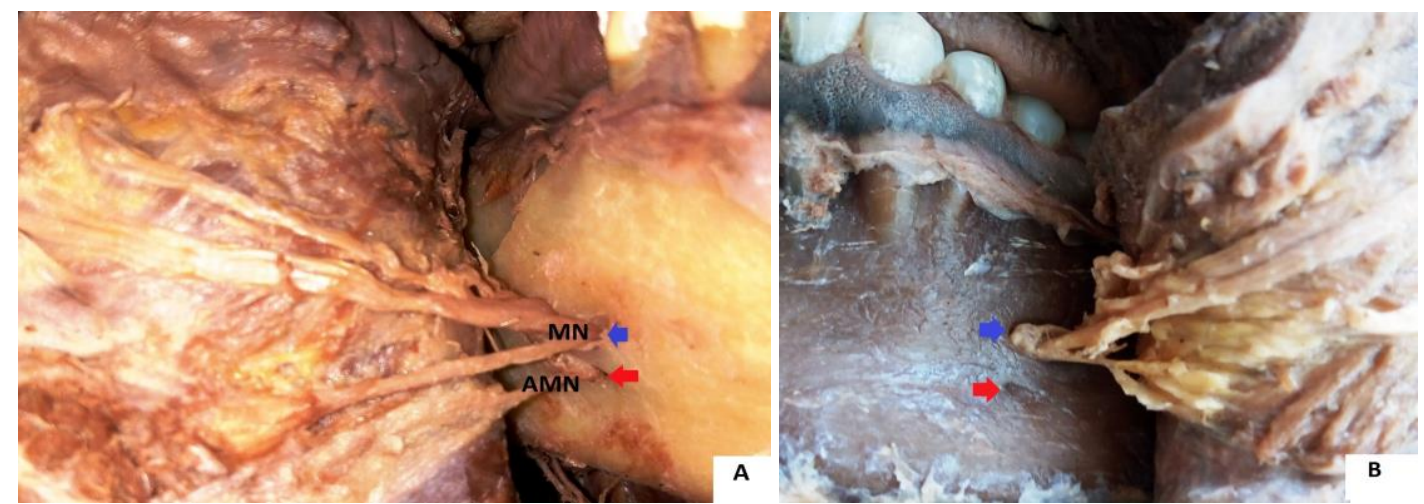

Fig. 2: Photograph showing mental and accessory mental foramina; 2A: Accessory mental nerve (AMN) coming from accessory mental foramen and mental nerve (MN); 2B: Presence of accessory mental foramen (red arrow head) without any significant structure passing through it.

Arrow head (blue) - Mental nerve emerging at mental foramen 
Table 1: Mental foramen location

\begin{tabular}{|l|c|c|c|}
\hline Mental foramen & $\begin{array}{c}\text { Right } \\
(\mathbf{n = 3 0})\end{array}$ & $\begin{array}{c}\text { Left } \\
(\mathbf{n = 3 0})\end{array}$ & $\begin{array}{c}\text { Total } \\
(\mathbf{n = 6 0})\end{array}$ \\
\hline PM1 & $08(26 \%)$ & $08(26 \%)$ & $16(26.66 \%)$ \\
\hline PM2 & $20(66 \%)$ & $20(66 \%)$ & $40(66.66 \%)$ \\
\hline PM1 \&PM2 & $02(6.6 \%)$ & $02(6.6 \%)$ & $04(6.66 \%)$ \\
\hline
\end{tabular}

PM1 - First premolar

PM2 - Second premolar

Table 2: Location of accessory mental foramina

PM1 - First premolar

\begin{tabular}{|l|c|c|c|}
\hline \multicolumn{1}{|c|}{ Location } & $\begin{array}{c}\text { Right } \\
(\mathbf{n = 3 0})\end{array}$ & $\begin{array}{c}\text { Left } \\
(\mathbf{n = 3 0})\end{array}$ & $\begin{array}{c}\text { Total } \\
(\mathbf{n = 6 0})\end{array}$ \\
\hline Canine & 2 & 1 & $3(5 \%)$ \\
\hline Canine \& PM1 & 1 & 0 & $1(1.66 \%)$ \\
\hline PM2 & 0 & 1 & $1(1.66 \%)$ \\
\hline PM2 \&M1 & 1 & 0 & $1(1.66 \%)$ \\
\hline Total & $4(13.3 \%)$ & $2(6.6 \%)$ & $6(10 \%)$ \\
\hline
\end{tabular}

PM2 - Second premolar

Table 3: Number of branches of mental nerve at its emergence

\begin{tabular}{|l|c|c|c|c|c|}
\hline $\begin{array}{c}\text { Number of branches } \\
\text { from MN }\end{array}$ & $\begin{array}{c}\text { Right } \\
(\mathbf{n = 3 0})\end{array}$ & $\begin{array}{c}\text { Percentage } \\
(\boldsymbol{\%})\end{array}$ & $\begin{array}{c}\text { Left } \\
(\mathbf{n = 3 0})\end{array}$ & $\begin{array}{c}\text { Percentage } \\
(\boldsymbol{\%})\end{array}$ & $\begin{array}{c}\text { Total } \\
(\mathbf{n = 6 0})\end{array}$ \\
\hline Double(Type I) & 14 & $46 \%$ & 17 & $56 \%$ & $51.66 \%$ \\
\hline Triple (Type-II) & 09 & $30 \%$ & 09 & $30 \%$ & $30 \%$ \\
\hline Four (Type- III) & 07 & $23.34 \%$ & 04 & $13.34 \%$ & $18.34 \%$ \\
\hline
\end{tabular}

\section{Discussion}

The knowledge about likely variations in position, course and pattern of emergence of $\mathrm{MN}$ at $\mathrm{MF}$ is essential in gaining adequate nerve block of $\mathrm{MN}$ during surgical procedures. Many potential inadvertent complications of neurosensory alterations in the chin and lower lip can be avoided by locating MF with emerging neurovascular bundle. ${ }^{9}$ The position of MF with MN branching pattern has been described to show racial variations. ${ }^{10}$ The current study thus observed the possible variations with $\mathrm{MF}$, AMF and neurovascular structures emerging via cadaveric dissection on South Indian population. Findings of current study will help validating findings available on South Indian population obtained through osteological studies.

The most frequent location of MF in the current study was found to be inferior to the second premolar tooth $(66 \%)$. This is in accordance with the previous studies which also found the location of MF in relation to second premolar tooth in various ethnic groups. ${ }^{11-13}$ An osteological study done on South Indian population by Sankar et al (2011) found $54.1 \%$ of MF present at the apex of second premolar similar to the current study. ${ }^{14}$ The neurovascular bundle emerging from it has been found very crucial from surgical point of view. In the current study, a single mental nerve was found to be emerging at MF in all dissected cadavers on both sides. A single MN was found emerging from corresponding foramen in all the cadavers on both sides. No instances of unilateral or bilateral absence of $\mathrm{MN}$ were noted as reported in previous studies. ${ }^{15}$

Though mental nerve is seen emerging as a single trunk, the prevalence of double mental nerves is not rare. It has been documented within a range of 1 to $10.6 \%$ of cases. ${ }^{16,17}$ Even though few osteological studies have reported presence of double mental nerves, its validation under gross cadaveric observation was essential. A cadaveric dissection on 60 hemi faces revealed a prevalence of $4.7 \%$ occurrence of double mental nerves in Kenyan population. ${ }^{18}$ The current study however didn't reveal any occurrence of double mental nerve on dissection which is a variance from above literatures. This might be suggestive of low incidence of double mental nerves in South Indian population.

The MN after emerging from MF, branches of to supply the chin and lower lip and gingiva. ${ }^{19}$ Multiple failed attempts of nerve block of lower jaw can be prevented by proper knowledge about mode of branching of MN. The current study revealed the MN dividing into two to four branches at its emergence from MF. The most common pattern observed was division of the MN into two branches on both sides (51.66\%) within 1-2mm of MF followed by division of MN into three branches (30\%). The medial branch further divided into two branches to innervate mental region and the medial side of mucous membrane of lower lip. The lateral branch further divides into two and supplied the lateral side of lip and angle of mouth. 
The gingival branches were seen to be given from either of the labial branches. The branches of mental nerve have been reported to vary from one to four as reported in previous studies. ${ }^{2}$ Hu et al (2007) divided the branching pattern of MN into 5 types based on its distribution area and number of nerve branches. ${ }^{20} \mathrm{He}$ described 4 terminal branches of the mental nerve as angular, medial inferior labial, lateral inferior labial, and mental branches. The common type was the MN dividing into 3 initial branches where two medial branches supply the chin and medial part of lower lip independently while the lateral one further divides further into two smaller branches for lateral part of lip and corner of mouth. A similar cadaveric dissection study done on Kenyan population which described the initial and terminal branching pattern of $\mathrm{MN}$ also showed MN dividing into 1 to 4 initial branches. ${ }^{18}$ The MN divided into 2 branches in 39\% cases while in 19\% it continued as a single trunk. However in the current study, MN continuing as a single trunk was not seen. This is similar to findings of Hu et al (2007) and Alsaad et al (2003) who also noted the MN was seen splitting into 2 to 4 branches. ${ }^{18,21}$ The characteristic pattern of MN dividing into three branches was only noted in $30 \%$ of cases on both the sides as compared to $61.3 \%$ of Korean and $55.6 \%$ of Ireland population. ${ }^{20,22}$ This suggests a possibility of high level of ethnic variation among different population regarding the branching pattern of MN.

The mental foramen in human is usually single in number. Any additional foramen thus found in the vicinity of MF is termed as AMF. AMF usually forms when MN branches prior to formation of MF which gives passage to a branch of $\mathrm{MN}$ or a branch of inferior alveolar nerve. ${ }^{23}$ Different variants of AMF might have occurred due to epigenetic traits undergoing modifications during ontogeny with variable degrees of expression. Hence it is suggested that genetic modifications might be responsible for variations encountered in AMF regarding its number, size, position and shape. ${ }^{24}$ These variability has been described by osteological, cadaveric dissections and radiological studies on different population. The incidence reported is around 1.5\% in Russians, $2.6 \%$ in French, $2.8 \%$ in Israeli population 3\% in Hungarians, $3.3 \%$ in Greeks, $3.6 \%$ in Egyptians, $4 \%-5.7 \%$ in Americans, $9.7 \%$ in Melanasians, $12.5 \%$ in Polynesians. ${ }^{1,25-27}$ An osteological study revealed an incidence of $8.85 \%$ of AMF, indicating a high prevalence of its occurrence in South Indian population. ${ }^{28}$ The current cadaveric study reported an incidence of $10 \%$ AMFs which is in accordance with this osteological data. These AMFs were most frequently found on the right side $(13.3 \%)$ which is similar to data obtained by Pokhrel et al (2013), where out of 166 sides examined, right side AMFs seen in $11.3 \%$ cases of males and $3.3 \%$ cases of females. ${ }^{29}$ Voljevica et al (2015) also described the presence of all four $\mathrm{AMF}$ to be situated on the right side of the mandible. ${ }^{30}$ Toh et al (1992) suggested the same with his findings of two right sided AMF out of three cases. ${ }^{23}$ On the contrary, few osteological studies done on Indian population by Singh and Srivastav (2010), ${ }^{31}$ Udhaya et al (2013) on South Indian population also showed the occurrence of AMFs on left side. ${ }^{26} \mathrm{~A}$ similar study on 260 dry mandibles by Rajkohila et al(2018) also found the AMFs to be mostly located on the left side than the right side. ${ }^{28}$ This discrepancy could be due to small sample size in the current cadaveric study.

The distribution of AMF has reported to show variability in relation to lower teeth. It can be located below the first molar tooth ${ }^{31,32}$ second premolar ${ }^{28}$ or between second premolar and first molar. In the present study, while it was present in various locations, out of 6 AMFs, $3(5 \%)$ found below the canine. Despite the fact that six AMFs were found, AMN was seen transmitted through it only in one case $(3.3 \%)$. This AMF was situated between second premolar and first molar. This proposes that AMF in this region was of clinically relevant.

The distribution of AMN over mental region can be related to position of AMF in respect to MF because the fibers of AMF seem to supplement some areas which are not supplied by MN. ${ }^{33}$ The AMN can branch off directly from inferior alveolar nerve or may be given as a terminating branch of MN. In the presence of $\mathrm{AMN}$, the $\mathrm{MN}$ was seen to divide into 3 main branches in current study. The only innervation to mental area was seen coming from branches of AMN. Although six AMF were noted in the current study, not all AMF exhibited the AMN emerging from it. In only one case a single $\mathrm{AMN}$ was noted emerging through $\mathrm{AMF}$ and it innervated the mental area separately. On a similar cadaveric dissection the prevalence of AMN in Kenyan population was found to be $1.6 \% .{ }^{18}$ Several other osteological studies described its prevalence in different population as $2.6 \%$ in French, $1.5 \%$ in Russia, and $12.5 \%$ in Polynesians and $1.4 \%-5.7 \%$ in Americans. ${ }^{1,25-27}$ Nevertheless the presence of AMFs on dry mandibular study cannot confirm the nature of structures passing through it. In fact Fuakami et al (2011) reported cases where few capillaries were only seen traversing through the foramen without AMN. ${ }^{8}$ The current study also confirmed the observations of Fuakami et al.

The AMN when present described to supply the mucous membrane of lip to corner of mouth. ${ }^{23}$ The precise knowledge about the location of MF with AMF and territory of innervations of AMN in relation to MN is essential during planning of dental implant procedures and selection of osteotomy sites. ${ }^{34}$ The osteological study by Rajkohila et al (2018) showed the location of AMF mostly either inferolateral or superomedial to MF within a mean distance of $2.96 \mathrm{~mm}$ from MF. Some previous studies reported the mean 
distance between the AMF and MF as $3.3 \mathrm{~mm}, 2.86 \mathrm{~mm}$ and $2.54 \mathrm{~mm}$ respectively, ${ }^{35-37}$ while some authors noted the mean MF-AMF distance as high as $6.3 \mathrm{~mm}$ and $5.2 \mathrm{~mm}$, respectively. ${ }^{16,38}$ The current study found the single case of AMF with AMN emerging through it at $3 \mathrm{~mm}$ infero lateral to $\mathrm{MF}$ in between second premolar and first molar which falls within the range of previous findings. The distance of AMF and MF plays a decisive role while planning for any implant in mandibular region to avoid injury to neurovascular structures exiting AMF.

\section{Conclusion}

In South Indian population, a single $\mathrm{MN}$ was observed emerging from MF on dissection on both sides without any absence or double MNs. It was found to divide into two main branches close to foramen in most cases. The prevalence of AMFs although described high in this population, cadaveric dissection confirmed that not all AMFs exhibit AMN through it. This report would provide surgeons a better understanding of neurovascular structures over this area during dental procedures in regards to South Indian population.

Financial Support and Sponsorship: This study was financially supported by Fluid research Grant, Christian Medical College, Vellore

\section{Conflict of Interest: There are no conflicts of interest}

\section{References}

1. Amorim MM, Prado FB, Borini CB. The mental foramen position in dentate and edentulous Brazilian's mandible. Int J Morphol. 2008;26(4):981-987. doi: 10.4067/s071795022008000400033.

2. Kieser J, Kuzmanovic D, Payne A, Dennison J, Herbison P. Patterns of emergence of the human mental nerve. Arch Oral Biol. 2002;47(10):743-747.

3. Fabian FM. Position, shape and direction of opening of the mental foramen in dry mandibles of Tanzanian adult black males. Ital J Anat Embryol. 2007;112(3):169-177

4. Standring S, Ellis H, Healy JC, et al: Gray's Anatomy (ed 39). London, Churchill Livingstone, 2005, p513.

5. Moore KL, Dalley AF: Clinically Oriented Anatomy (ed 5). Philadelphia, PA, Williams \& Wilkins, 2006, p 978.

6. Fishel D, Buchner A, Hershkowith A, Kaffe I. Roentgenologic study of mental foramen. Oral Surg Oral Med Oral Pathol. 1976;41:682-6.

7. Thakur G, Thomas S, Thayil SC, Nair PP. Accessory mental foramen: a rare anatomical finding. BMJ Case Rep. 2011 doi: 10.1136/ bcr.09.2010.3326.

8. Fuakami K, Shiozaki K, Misima A, Shimoda S, Hamada Y, Kobayashi K. Detection of buccal perimandibular neurovascularisation associated with accessory foramina using limited cone-beam computed tomography and gross anatomy. Surg Radiol Anat. 2011;33(2):141-146.

9. Haghanifar S, Rokouei M. Radiographic evaluation of the mental foramen in a selected Iranian population. Indian $J$ Dent Res. 2009;20:150-152.

10. Agthong S, Huanmanop T, Chentanez V. Anatomical variations of the supraorbital, infraorbital, and mental foramina related to gender and side. J Oral Maxillofac Surg. 2005; 63(6):800-804.

11. Yesilyurt H, Iydinlioglu A, Kavakli A, Ekinci N, Eroglu C. Local differences in the position of the mental foramen. Folia Morphol. 2008;67:32-35.

12. Philips JL, Weller RN, Kulild JC. The mental foramen: Part II. Radiographic position in relation to the mandibular second premolar. Journal of Endodontics. 1992;18(6):271-4.

13. Khojastepour L, Mirbeigi S, Mirhadi S, Safaee A. Location of Mental Foramen in a Selected Iranian Population: A CBCT Assessment. Iran Endod J. 2015;10(2):117-121.

14. Sankar DK, Bhanu SP, Susan PJ. Morphometrical and morphological study of mental foramen in dry dentulous mandibles of South Andhra population of India. Indian J Dent Res. 2011;22:542-6.

15. Hasan T, Fauzi M, Hasan D. Bilateral absence of the mental foramen: a rare variation. International Journal of Anatomic Variations. 2010;3:167-169.

16. Naitoh M, Hiraiwa Y, Aimiya H, Gotoh K, Ariji E. Accesory mental foramen assessment using cone-beam computed tomography. Oral surg Oral Med Oral Pathol Oral Radiol Endod. 2009;107(2):289-294.

17. Katakami K, Mishima A, Shiozaki K, Shimoda S, Hamada Y, Kobayashi K. Characteristics of accessory mental foramina observed on limited cone-beam computed tomography images. J Endod. 2008;34(12):1441-1445.

18. Loyal PK, Butt F, Ogeng'o JA. Branching Pattern of the Extraosseous Mental Nerve in a Kenyan Population. Craniomaxillofacial Trauma \& Reconstruction. 2013;6(4):251-256. doi:10.1055/s-0033135675

19. Williams, P.L., Bannister, L.H., Berry, M.M., Collins, P., Dyson, M., Dussek, J.E. and Ferguson, M.W. (1995) Gray's anatomy: The anatomical basis of medicine and surgery. 38th Edition, Churchill Livingstone, New York.

20. Hu KS, Yun HS, Hur MS, Kwon HJ, Abe S, Kim HJ. Branching patterns and intraosseous course of the mental nerve. J Oral Maxillofac Surg. 2007;65:2288-2294.

21. Alsaad K, Lee TC, McCartan B. An anatomical study of the cutaneous branches of the mental nerve. Int J Oral Maxillofac Surg. 2003;32(3):325-333.

22. Sawyer DR, Kiely ML, Pyle MA. The frequency of accessory mental foramina in four ethnic groups. Arch Oral Biol. 1998;43(5):417-420.

23. Toh H, Kodama J, Yanagisako M, Ohmori T. Anatomical study of the accessory mental foramen and the distribution of its nerve. Okajimas Folia Anat Jpn. 1992;69(2-3):85-88.

24. Hauser G, De Stefano GF. Epigenetic variants of human skull. Ed Schweizebart Stuttg. 1989;230-233.

25. Mamatha NS, Kedarnath NS, Singh M, Patel G. Accessory Mental Nerve: A Case Report. J Clin Diagn Res. 2013;7(9):2078-2079.

26. Udhaya K, Saraladevi KV, Sridhar J. The Morphometric Analysis of the Mental Foramen in Adult Dry Human Mandibles: A Study on the South Indian Population. $J$ Clin Diagn Res. 2013;7(8):1547-1551.

27. Hanihara T, Ishida H. Frequency variations of discrete cranial traits in major human populations. IV. Vessel and nerve related variations. J Anat. 2001;199(3):273-287.

28. Rajkohila J, Daniel P, Ambikaipakan S, Rabi S. Morphological and morphometric analysis of accessory mental foramen in dry human mandibles of south Indian population. Indian J Dent Res. 2018;29(1):56-60. 
29. Pokhrel R, Bhatnagar R. Position and number of mental foramen in dry human mandibles: Comparison with respect to sides and sexes. OA Anatomy. 2013;1(4):31.

30. Voljevica A, Talović E, Hasanović A. Morphological and morphometric analysis of the shape, position, number and size of mental foramen on human mandibles. Acta Medica Academica. 2015;44(1):31-38.

31. Singh R, Srivastav AK. Study of Position, Shape, Size and Incidence of Mental Foramen and Accessory Mental Foramen in Indian Adult Human Skulls. Int J Morphol. 2010;28(4):1141-1146.

32. Cağirankaya LB, Kansu H. An accessory mental foramen: a case report. J Contemp Dent Pract. 2008;9(1):98-104.

33. Iwanaga J, Saga T, Tabira Y, Nakamura M, Kitashima $\mathrm{S}$, Watanabe $\mathrm{K}$ et al. The clinical anatomy of accessory mental nerve and foramina. Clin Anat. 2015;28(7):84856.

34. Torres MGG, Valverde L de F, Vidal MTA, CrusoéRebello IM. Accessory mental foramen: A rare anatomical variation detected by cone-beam computed tomography. Imaging Sci Dent. 2015;45(1):61-65.

35. Garay I, Cantin M. Accessory mental foramina assessed by cone-beam computed tomography: Report of unilateral and bilateral detection. Int J Morphol. 2013;31(3):11041108 .
36. Polakowska EZ, Radwański M, Łęski M, Ledzion S, Szymańska ML, Polguj M. The assessment of accessory mental foramen in a selected polish population: a CBCT study. BMC Med Imaging. 2017;17:1.

37. Goregen M, Miloglu O, Ersoy I, IS Bayrakdar, Akgul HM. The assessment of accessory mental foramina using cone-beam computed tomography. Turk J Med Sci. 2013;43(3):479-483.

38. Kalender A, Orhan K, Aksoy U. Evaluation of the mental foramen and accessory mental foramen in Turkish patients using cone-beam computed tomography images reconstructed from a volumetric rendering program. Clin Anat. 2012;25(5):584-592.

How to cite this article: Rout $S$, Daniel $P$, Suganthy J. Branching pattern of mental nerves in south Indian population: A cadaveric dissection study. Indian J Clin Anat Physiol. 2018;5(4):540-545. 